\title{
Ice Nucleation and Propagation in Cranberry Uprights and Fruit Using Infrared Video Thermography
}

\author{
Beth Ann A. Workmaster ${ }^{1}$ and Jiwan P. Palta ${ }^{2}$ \\ Department of Horticulture, University of Wisconsin, Madison, WI 53706
}

Michael Wisniewski ${ }^{3}$

U.S. Department of Agriculture, Agricultural Research Service, 45 Wiltshire Rd., Kearneysville, WV 25430

\begin{abstract}
AdDitIONAL INDEX WORDS. Vaccinium macrocarpon, exotherm, freezing stress resistance, fruit, ice formation, low temperature, supercooling

Abstract. Infrared video thermography was used to study formation of ice in leaves, stems, and fruit of cranberry (Vaccinium macrocarpon Ait. 'Stevens'). Ice formed on the plant surface at $-1 \mathrm{or}-2{ }^{\circ} \mathrm{C}$ by freezing of a droplet of water containing ice nucleation-active bacteria (Pseudomonas syringae van Hall). Samples were then cooled to a minimum of $-8^{\circ} \mathrm{C}$. Observations on the initiation and propagation of ice were recorded. Leaves froze only when ice was present on the abaxial surface. Once initiated, ice propagated to the stem and then readily to other leaves. In both unripe and ripe fruit, ice propagation from the stem to the fruit via the pedicel was not observed. Fruit remained supercooled for up to 1 hour after ice was present in the stem. Fruit could only be nucleated when ice was present at the calyx (distal) end. Red (ripe) berries supercooled to colder temperatures and for longer durations than blush (unripe) berries before an apparent intrinsic nucleation event occurred. These observations provide evidence that leaves are nucleated by ice penetration via stomata. The ability of fruit to supercool appears to be related to the presence of barriers to extrinsic ice propagation at both the pedicel and fruit surface. Stomata at the calyx end of the fruit in the remnant nectary area may provide avenues for extrinsic ice nucleation.
\end{abstract}

Freezing injury can occur in plants only after the formation of ice within their tissues. Knowledge of the patterns of ice nucleation and propagation and the nature of potential ice nucleating agents is important to understanding freezing-stress-resistance mechanisms in plants and for the development of frost control strategies (Ashworth, 1992; Lindow et al., 1982). Ice formation in plants has been studied by thermal analyses (Ashworth and Davis, 1984; Ashworth et al., 1985; Cary and Mayland, 1970; Proebsting et al., 1982; Quamme et al., 1972; Yelenosky, 1991). These techniques of measuring the heat released by freezing water in plants, however, do not yield direct data about either the location of ice initiation or the temperature at that location. Microscopic techniques can reveal sites of ice formation and accumulation (Ashworth et al., 1992; Pearce and Ashworth, 1992), but the sites of ice initiation must also be inferred in these cases. Nuclear magnetic resonance microimaging (Price et al., 1997) shows patterns of freezing in complex organs, such as the flower buds of woody plants, but does not allow for the viewing of such events over larger pieces of plant material or whole plants, or for viewing the freezing events in real time.

Infrared (IR) video thermography has recently been used to visualize ice nucleation and propagation in plants (Ceccardi et al.,

Received for publication 26 Mar., 1999. Accepted for publication 8 July 1999. This work was supported by the College of Agriculture and Life Sciences, University of Wisconsin (UW), Madison, and by the Wisconsin State Cranberry Growers Association. We thank the staff of the UW, Madison Biotron and Heidi Barnhill of the Russell Laboratories Scanning Electron Microscopy Facility for their technical assistance, as well as Mustafa Özgen for assistance with the SEM work. The cost of publishing this paper was defrayed in part by the payment of page charges. Under postal regulations, this paper therefore must be hereby marked advertisement solely to indicate this fact.

${ }^{1}$ Graduate research assistant.

${ }^{2}$ Campbell-Bascom professor of horticulture, to whom reprint requests should be addressed; email: jppalta@facstaff.wisc.edu.

${ }^{3}$ Scientist.
1995; Fuller and Wisniewski, 1998; Le Grice et al., 1993; Wisniewski and Fuller, 1999; Wisniewski et al., 1997). With this method, freezing events are imaged as water freezes and the heat of fusion is released. Recent improvements in temperature sensitivity, accuracy, and spatial resolution have increased the potential for using IR thermography to study the location of ice nucleation, as well as the direction and rate of ice propagation (Wisniewski et al., 1997). Freezing events in intact plant tissue can also be observed in real time with IR video thermography. By observing the occurrence of freezing events as well as the extent of subsequent ice propagation, low temperature survival mechanisms (tolerance or avoidance of ice formation) of various plant parts can be determined.

Ice formation in plants can be induced by either intrinsic (Andrews et al., 1986; Gross et al., 1988) or extrinsic (Lindow, 1995; Lindow et al., 1982) sources. Once ice has been initiated, barriers and avenues to ice propagation, both within the plant and at the plant surfaces, determine the subsequent pattern of ice formation and are a factor in the survival mechanism (tolerance of extracellular ice or avoidance of ice by supercooling) employed by a given plant tissue or organ. Barriers to ice propagation within a plant can be permanent or temporary (i.e., propagation is impeded until growth of ice crystals can continue). Some barriers may also only be present at particular times of the year, or upon completion of particular stages of development. Supercooling of the buds of some temperate woody species appear to be, at least in part, related to cell shape and structure in the bud axis area (Ashworth, 1982; Quamme et al., 1995) and a lack of vascular differentiation (Ashworth, 1982, 1984; Ashworth et al., 1992) during the dormant period. In wheat (Triticum aestivum L.), the propagation of ice was impeded for several hours at stem and rachis nodes (Single, 1964). Avenues to ice propagation require areas (Pearce and Ashworth, 1992) and pores (Ashworth and Abeles, 1984) large enough for ice crystals to grow. Wounds, 
Table 1. Average lag time between freezing events in uprights. In each type of experiment, uprights were inoculated with one or more droplets of $\mathrm{Ice}^{+}$bacteria suspension. In the first two experiment types, ice propagated from frozen bacterial droplets into the plant material, while in the third case, ice propagated from the frozen stem and leaves to the bacterial droplets.

\begin{tabular}{|c|c|c|c|}
\hline \multicolumn{2}{|l|}{$\begin{array}{l}\text { Experiment type } \\
\text { (freezing event) }\end{array}$} & \multirow{2}{*}{$\begin{array}{c}\text { Lag time } \\
\text { between } \\
\text { events (min) }\end{array}$} & \multirow{2}{*}{$\begin{array}{c}\text { Uprights } \\
\text { tested } \\
\text { (no.) }\end{array}$} \\
\hline First & Second & & \\
\hline Bacterial droplet at cut stem surface & Upright stem & $0.7 \pm 0.8^{\mathrm{z}}$ & 7 \\
\hline Bacterial droplet on abaxial leaf surface & Upright leaf to stem & $18.6 \pm 6.9$ & 9 \\
\hline Upright stem and leaves & Bacterial droplets on abaxial leaf surface & $3.2 \pm 1.0$ & 10 \\
\hline
\end{tabular}

${ }^{\mathrm{z}}$ Values are means \pm SD.

cracks in the cuticle and epicuticular waxes, lenticels, and open stomata have all been suggested as possible entry points for extrinsic sources of ice, while extracellular spaces and xylem vessels are thought to function as pathways of internal ice propagation (Levitt, 1980). Ice formation has been observed microscopically in subepidermal areas and substomatal cavities in freeze-fixed field samples (Pearce and Ashworth, 1992), although it is not known if such ice formation is intrinsically induced, or if ice present on the leaf surface propagates through stomata and induces freezing by inoculation. Many types of fruit have been noted to supercool (Lucas, 1954, Proebsting et al., 1982). In both lemons (Citrus limon (L.) Burm.) (Lucas, 1954) and young developing fruit of peach (Prunus persica L. Batsch), sweet cherry (Prunus avium L.), and pear (Pyrus communis L.) (Proebsting et al., 1982), detached fruit were found to supercool to significantly colder temperatures than attached fruit. It has been assumed that ice nucleation of attached fruit occurs by growth of ice crystals in the stem and pedicel vascular tissue into the fruit (Andrews et al., 1986, Proebsting et al., 1982).

In this study, IR video thermography was used to study the formation of ice in various parts of fruit-bearing 'Stevens' cranberry (Vaccinium macrocarpon Ait.) shoots. The cranberry plant is a woody perennial vine native to wetland areas of northern North America. Fruit is borne on vertical stems (uprights) usually $\approx 15 \mathrm{~cm}$ in height, which grow from horizontal stems (runners). The cranberry upright is a good model system to investigate ice nucleation and propagation in intact (attached) fruit. Cranberry leaves are hypostomatous (Farag and Palta, 1989; Sawyer, 1932), making the upright also a good system to investigate the propagation of ice via stomata. Domesticated cranberries are cultivated in large, low-lying beds of peat and sand, areas that are often subject to frost events and periods of subfreezing temperatures (Dana, 1990). Thus, information gained on ice nucleation and propagation in a cranberry upright could be useful in developing frost protection strategies for this plant.

\section{Materials and Methods}

Temperature changes and freezing events in the plant material were monitored with an imaging radiometer (model 760; Inframetrics, North Billerica, Mass.) with a HgCdTe longwave (8 to $12 \mathrm{~mm}$ ) detector, as described by Wisniewski et al. (1997). Air temperatures were measured concurrently with a thermocouple placed in close proximity to the upright. Infrared images were recorded on videotape. For best resolution of exothermic events, a temperature span of $2{ }^{\circ} \mathrm{C}$ was selected on the radiometer monitor. Colors of the temperature span ranged from pink (colder) to yellow (warmer). The midpoint of this range was lowered manually as the temperature decreased to ensure that exothermic events would be seen. Objects colder than the given temperature span appeared black while objects warmer than the span appeared white.

Samples of nonfruiting and fruiting uprights and detached fruit were used in this study. The maturity of fruit ranged from unripe (white or blush) to ripe (red). Uprights were collected from beds in central Wisconsin, transported to Madison on ice, and stored moistened with tap water in plastic bags at $4{ }^{\circ} \mathrm{C}$ until used for the experiments.

Experiments were conducted at the University of Wisconsin, Madison, Biotron facility in a dark plant growth room with a minimum temperature capacity of about $-8^{\circ} \mathrm{C}$. Plant material was blotted dry with tissue wipes before being placed in the room. Samples were equilibrated first at $0^{\circ} \mathrm{C}$ and then at -1 or $-2{ }^{\circ} \mathrm{C}$ for inoculation with ice nucleation-active (Ice ${ }^{+}$) bacteria (Pseudomonas syringae strain Cit7, or strain B728a). Bacterial cells were harvested and suspended in distilled water. Portions of uprights (stems, leaves, fruit) and detached fruit were inoculated with droplets of the $\mathrm{Ice}^{+}$bacteria suspension. Droplet size ranged from 0.5 to $3 \mu \mathrm{L}$ for leaves and stems, and from 4 to $8 \mu \mathrm{L}$ for fruit (larger droplets needed for adhesion to fruit surfaces). Following inoculation and reequilibration, samples were cooled in steps of one to two at 10 - to 20 - min intervals to about $-8{ }^{\circ} \mathrm{C}$, or until freezing occurred in the plant tissue. Since the main purpose of the experiments was to observe patterns of ice propagation after nucleation was initiated (which took place at -1 to $-2{ }^{\circ} \mathrm{C}$ ), it was not necessary to maintain identical cooling rates in different experimental setups. Experimental runs ranged from $20 \mathrm{~min}$ to up to $2 \mathrm{~h}$ (in general, shorter times for stem and leaf runs, longer times for fruit runs). Samples were protected from air currents in the room by surrounding the stand (a plant cart) on four sides with clear polyethylene sheeting. Experiments were conducted in Fall 1996 and 1997. Each type of experiment was repeated at least five times. Representative images were selected for presentation.

The structure of the fruit calyx (distal) end was investigated by scanning electron microscopy (SEM). Calyx tissue was removed with a razor blade. Unfixed excised fruit ends were sputter-coated with gold and viewed with a Hitachi S-570 scanning electron microscope (Hitachi, Tokyo) at $10 \mathrm{kV}$.

\section{Results}

STEMS AND LEAVES. Within $\approx 1$ min of placing droplets of a suspension of Ice ${ }^{+}$bacterial cells on cut stem surfaces and on both leaf surfaces at $-1{ }^{\circ} \mathrm{C}$, unfrozen droplets appeared black, indicating that water droplets were colder than the plant material. This is presumably due to evaporative cooling. When several droplets 

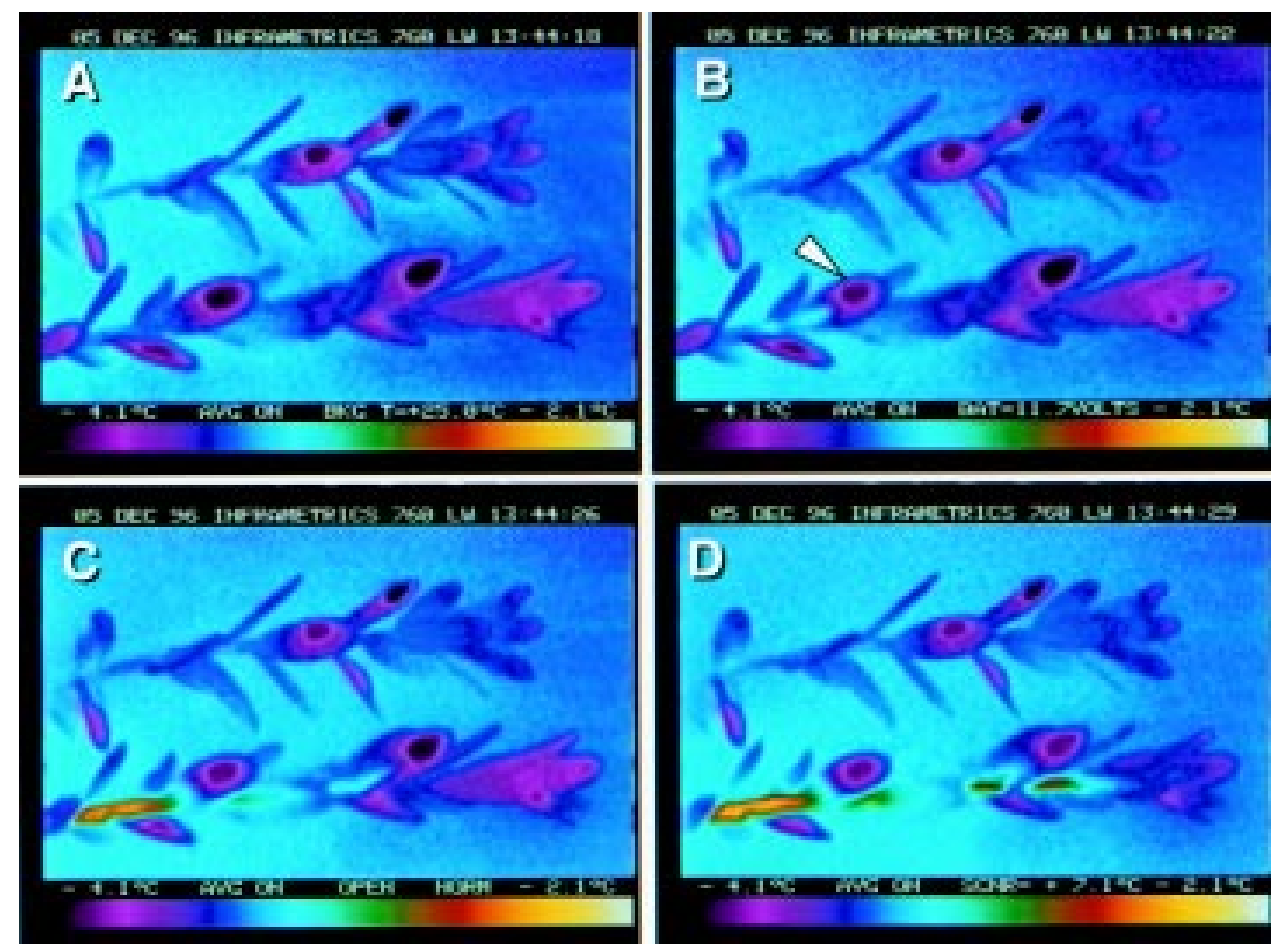

Fig. 1. Propagation of ice from abaxial leaf surface to stem and other leaves of the upright. In both uprights shown, different leaves were inoculated with droplets of Ice ${ }^{+}$bacteria suspension on either their abaxial or adaxial sides. The upper upright was already frozen at the time of observation. In the lower upright, ice was able to propagate from a frozen bacterial droplet $(3 \mu \mathrm{L})$ on an abaxial surface of a leaf into the stem in the following sequence: (A) bacterial droplets nucleated between -2 and $-3{ }^{\circ} \mathrm{C}$ (seen here as black areas at an air temperature of $-3.5^{\circ} \mathrm{C}$ ). The water in the plant tissue remained supercooled at this time. (B) ice propagated from a bacterial droplet (see arrow) into the leaf and a portion of the stem. At the moment of ice nucleation in the leaf, warming from the exotherm caused the bacterial droplet to appear smaller. (C) and (D) ice propagated quickly along the stem, entering other leaves and terminating at the tip of the upright. in association with frozen droplets only when droplets were placed on abaxial leaf surfaces (Fig. 1). Ice initiation was never seen in association with bacterial droplets placed on the adaxial surfaces of leaves. Leaves and stems did not nucleate quickly upon the freezing of the abaxial bacterial droplets, as was seen in the case of the cut stem surface (Table 1). Instead, there was an average lag period of $18.6 \pm 6.9 \mathrm{~min}$ from the time the nucleating droplet froze to the nucleation of the stem and other leaves along the upright. After a leaf did nucleate, ice propagated quickly into the stem and other leaves where its progress was unimpeded. From the first nucleated leaf, the direction of ice propagation was initially basipetal, then acropetal. Rates of ice propagation along the upright averaged 1.2 $\pm 0.4 \mathrm{~cm} \cdot \mathrm{s}^{-1}$. Ice propagation presumably occurred via the vascular tissue.

In a set of five runs (10 uprights), upright stems self-nucleated (air temperature between -6 and $-7.5^{\circ} \mathrm{C}$ ) before the bacterial droplets, and only droplets placed on abaxial leaf surfaces subsequently

Fig. 2. Propagation of ice from stem and leaves to supercooled Ice $^{+}$bacterial droplets (i.e., bacteria was ineffective). In cases like this, the stem self-nucleated first and ice propagated to the leaves, nucleating only those unfrozen bacterial droplets placed on abaxial leaf surfaces. (A) droplets of Ice $^{+}$bacteria $(3 \mu \mathrm{L})$ were placed on the abaxial and adaxial surfaces of six different leaves (gray arrows $=$ abaxial; white arrows $=$ adaxial). (B) stem self-nucleated at air temperature of $-7.5^{\circ} \mathrm{C}$. $(\mathbf{C})$ after $\approx 4 \mathrm{~min}$, only droplets on the abaxial leaf surfaces nucleated (exotherms indicated by yellow color). (D) up to $7 \mathrm{~min}$ later, none of the droplets on adaxial leaf surfaces froze were placed on different leaves of an upright, individual droplets were observed to freeze independently. Nucleation of these droplets typically occurred at about -1 to $-3{ }^{\circ} \mathrm{C}$. After droplets froze and the heat of fusion dissipated, droplet temperature was again lower than the plant surface temperature, indicated by their black appearance. This effect is possibly caused by sublimation.

Ice propagated easily into stems from frozen droplets at cut stem surfaces and subsequently traversed freely throughout the stem and other leaves. Ice nucleation at cut stem surfaces occurred an average of $0.7 \pm$ $0.8 \mathrm{~min}$ after the freezing of the bacterial droplet was initiated (Table 1). In three out of seven instances no time lag existed between nucleation of the droplet and subsequent propagation of ice into the stem.

Nucleation of leaves was observed
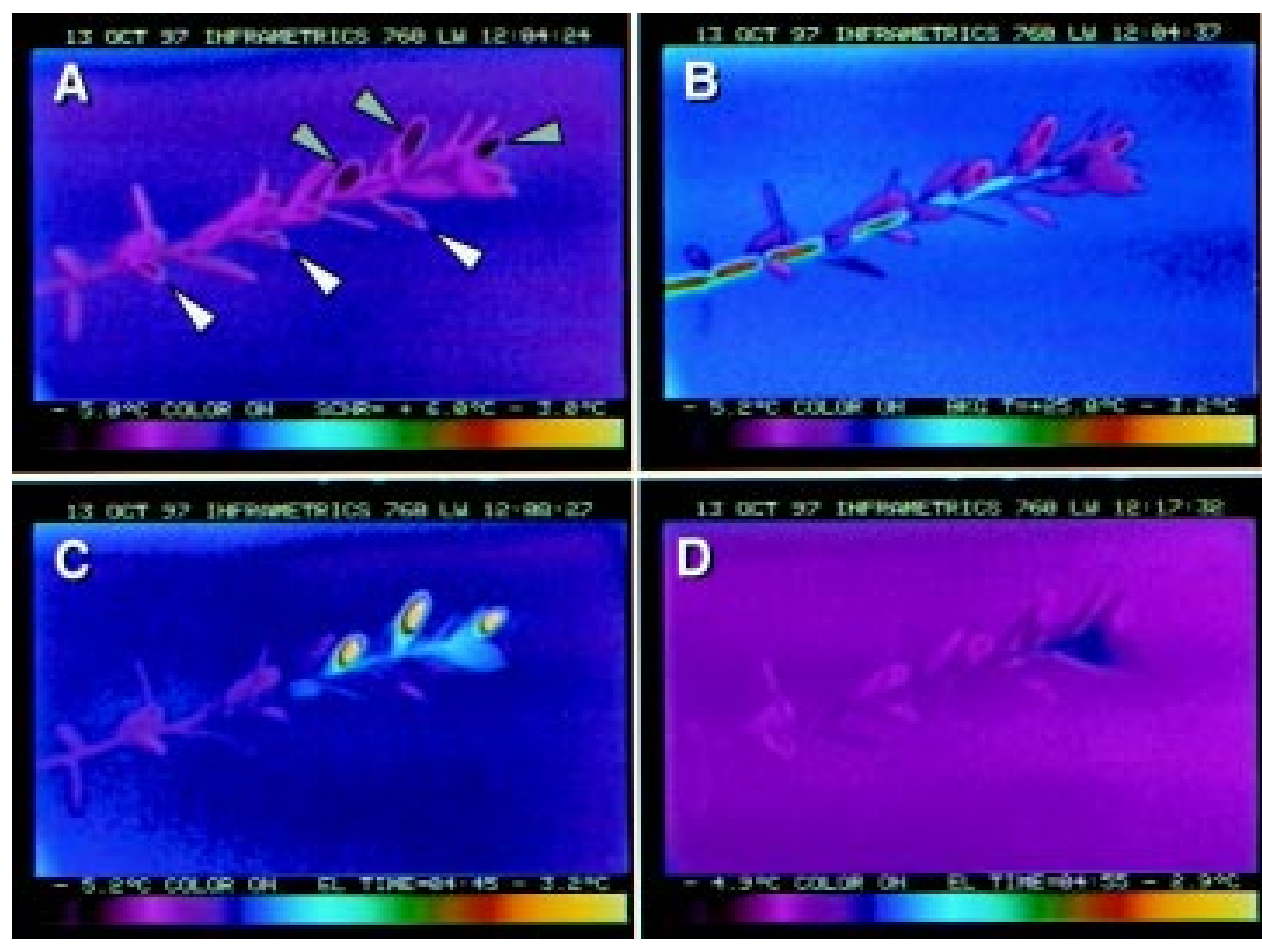

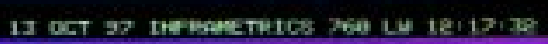

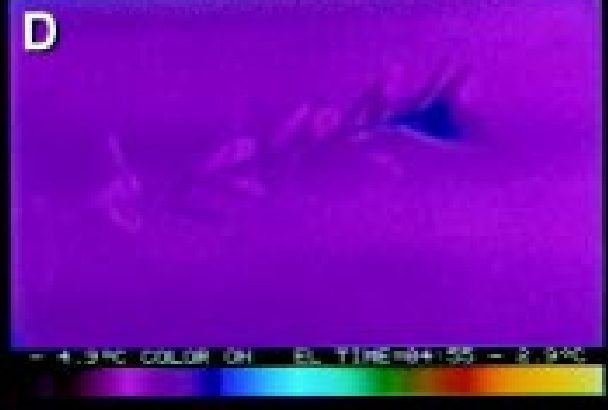



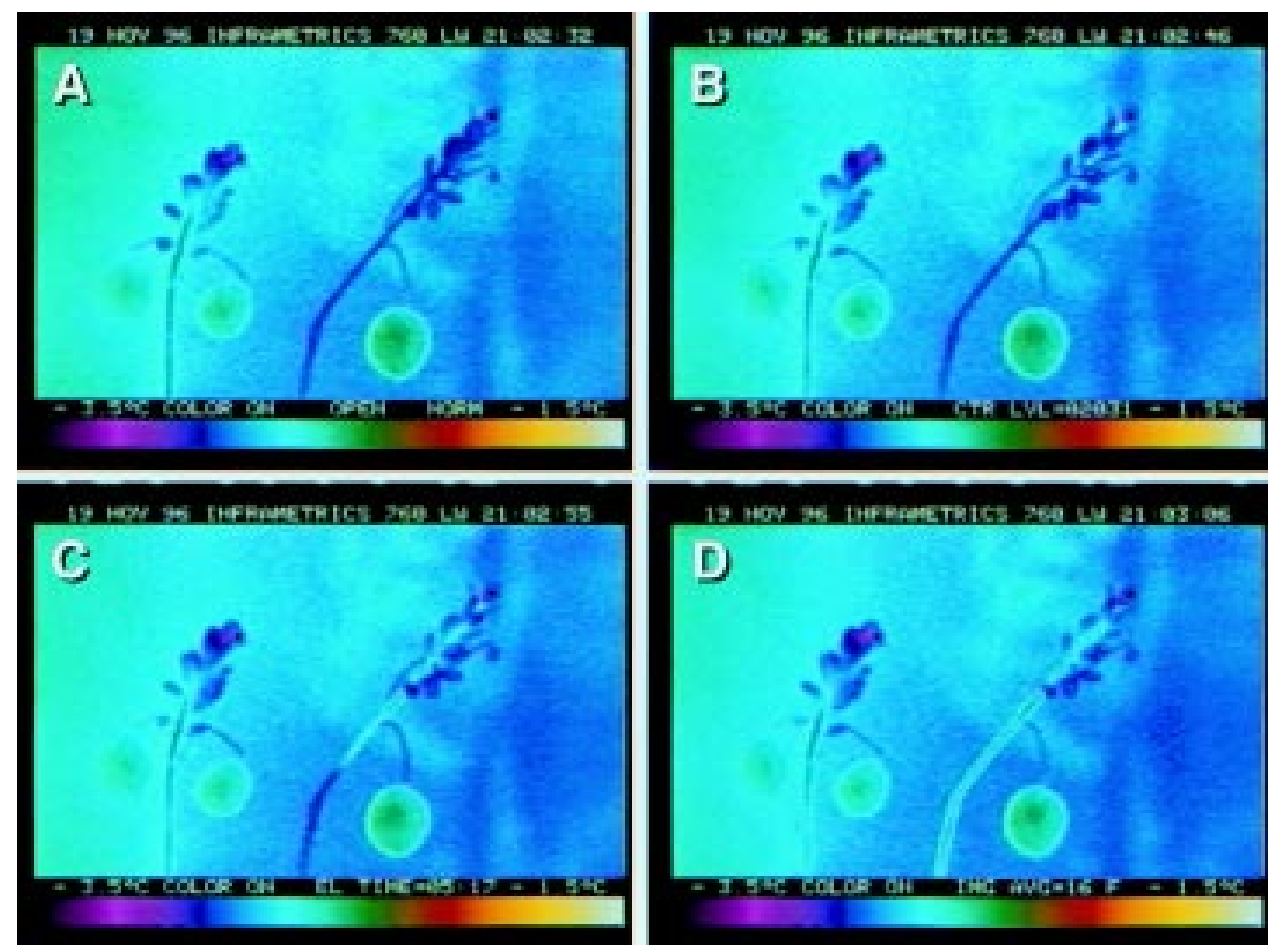

Fig. 3. Ice nucleation and propagation in upright with attached cranberry fruit. Ice did not propagate from the stem to ripening fruit through the pedicel. The tips of two uprights were cut and inoculated at the wound with droplets of Ice ${ }^{+}$ bacterial suspension $(3 \mu \mathrm{L})$. Ice nucleation had already occurred in the stem and leaves of the left upright. In the right upright: (A) at air temperature of $-2.4^{\circ} \mathrm{C}$, the leaves, stem, and fruit remained supercooled. (B) ice propagated into the stem from the frozen bacterial droplet. (C) ice continued propagating along the stem, but did not penetrate the pedicel. (D) the entire stem froze, with no change in either the pedicel or the fruit. This fruit continued to supercool for another $55 \mathrm{~min}$, freezing at around $-6^{\circ} \mathrm{C}$ from the calyx (distal) end, after being misted with water.

froze (Fig. 2). Supercooling of leaf surface droplets presumably occurred because the Ice ${ }^{+}$ bacteria did not function normally. In all of these cases, droplets on the abaxial surfaces nucleated by -6.5 to $-7.7^{\circ} \mathrm{C}$, within an average of $3.2 \pm 1.0 \mathrm{~min}$ from the freezing of the stem

Fig. 4. Ice nucleation and propagation in detached cranberry fruit. In all experiments, ice propagation was observed only from the calyx (distal) end of the fruit. Red (ripe) berries supercooled to colder temperatures and for longer durations than blush (unripe) berries. (A) four berries (two red, two blush) were positioned with either the calyx (distal) or pedicel (proximal) end up. These ends were inoculated with $8 \mathrm{~mL}$ of bacteria solution after fruit equilibrated at $-2{ }^{\circ} \mathrm{C}$ for $1 \mathrm{~h}$. (B) view of fruit after all bacterial droplets nucleated and cooled (thus appear black), before any freezing events in the fruits. $(\mathbf{C})$ the first fruit to begin freezing was the blush fruit inoculated at the calyx end (air temperature about $-4.5^{\circ} \mathrm{C}$ ). (D) four min later, the blush fruit inoculated at the pedicel end began freezing; however, the first ice formation actually occurred at the calyx end of this fruit (air temperature about $-5^{\circ} \mathrm{C}$ ). (E) the red fruit inoculated at the calyx end began freezing 23.5 min after the previous fruit (air temperature about $-5.2^{\circ} \mathrm{C}$ ) (F) the red fruit inoculated at the pedicel end never froze, supercooling to a minimum air temperature of about $-6{ }^{\circ} \mathrm{C}$ for $\approx 30 \mathrm{~min}$. to the freezing of individual droplets (Table 1). All droplets on the adaxial leaf surfaces remained unfrozen during this period (Fig. 2C). No delay occurred between the initial exotherm in the stem and the subsequent propagation of ice along the stem. In each case, the initial exotherm was observed in locations away from bacterial droplets.

Fruit. Both attached and detached fruit supercooled to about -6 to $-7^{\circ} \mathrm{C}$ for extended periods of time (Figs. 3 and 4). In contrast to the observation of ice propagating readily from the stem into leaves, no clear propagation was seen from the stem into the fruit pedicel (Fig. 3).

In all fruit experiments (both attached and detached fruit), ice nucleation of fruit tissue was only initiated at the calyx (distal) end of the fruit (Fig. 4). In general, the extent of freezing in fruit correlated well to the degree of subsequent watersoaking injury (data not shown). Fruit that had
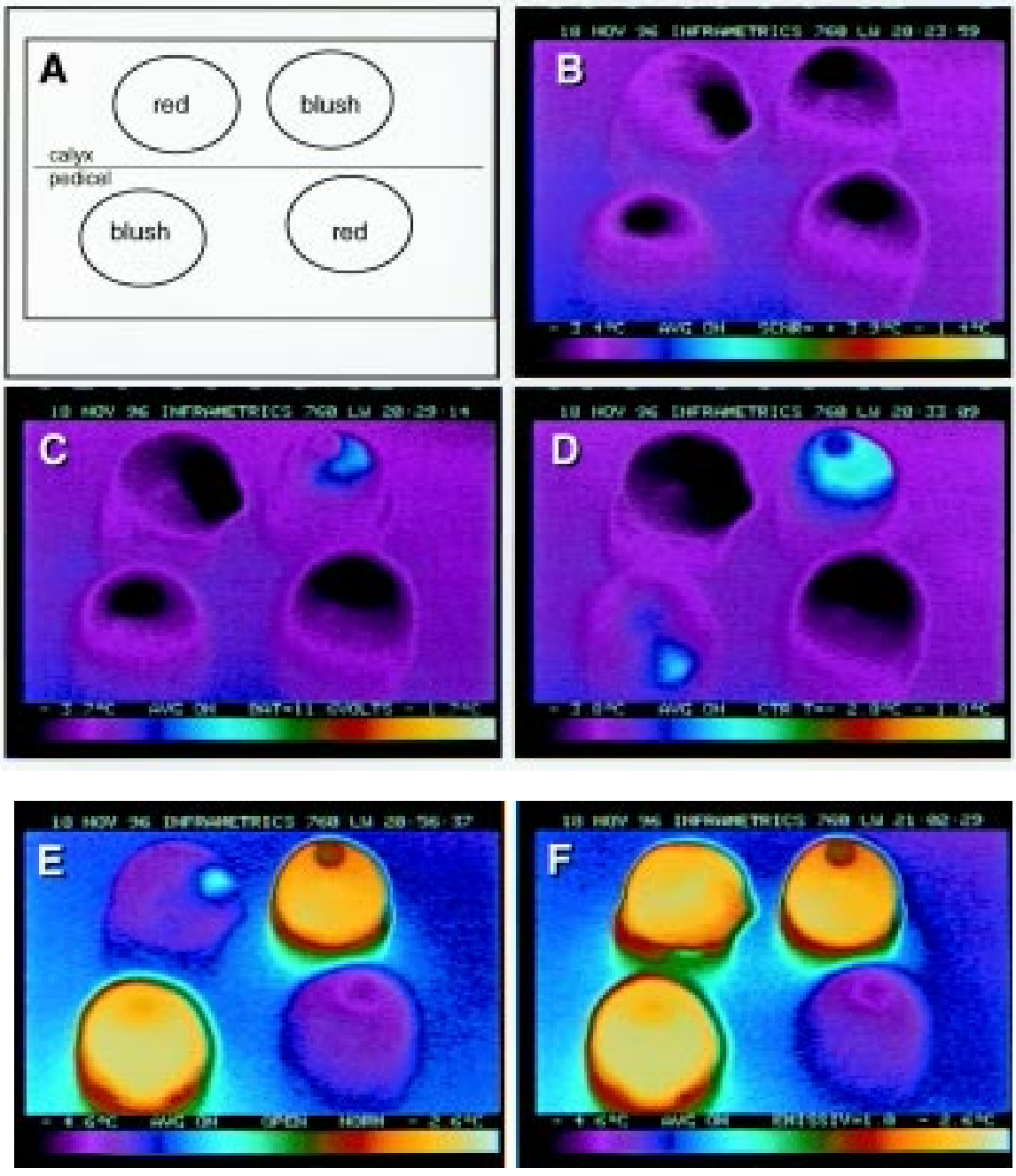
only just begun to nucleate at the time an experiment was terminated appeared to recover fully from the initial freezing stress. In two cases, unripe (white to light blush) fruit were observed to begin freezing at the calyx end even when they were inoculated at other locations (Fig. 4D). Bacterial droplets placed on the fruit surface or at the pedicel end were unable to induce ice formation in the fruit. This observation was repeated six times. Stomata were observed by SEM in the remnant area of the nectary (Fig. 5A and B). The nectary area is located in a ring of tissue between the anthers and the stigma, at the distal end of the ovary (Cross, 1953). These stomata were observed to be open to varying degrees.

Air temperatures when fruit nucleated ranged from -4 to -8 ${ }^{\circ} \mathrm{C}$. Red (ripe) berries supercooled typically to colder temperatures and for longer durations than blush or white (unripe) berries. In each of four experiments, three white and three red fruit were inoculated with bacterial droplets at the calyx end. Most of the white fruit $(92 \%)$ nucleated within 20 min of their bacterial drops freezing, while only one red fruit $(8 \%)$ nucleated during this time period. In fact, $67 \%$ of the red fruit never nucleated over the durations of the experiments $(\geq 1 \mathrm{~h}$ after freezing of the bacterial droplets on the fruit surface). The other red fruit that froze $(25 \%)$ nucleated between 21 to $32 \mathrm{~min}$ after nucleation of their bacterial droplets.

\section{Discussion}

Stems AND Leaves. Observations from this study provide evidence that stomata are the probable avenue through which ice penetrates into cranberry leaves, and that the cuticle on the adaxial leaf surface provides an adequate barrier to ice propagation. A distinct association was found between ice formation in a cranberry upright and the presence of a frozen bacterial droplet on abaxial leaf surfaces (Figs. 1 and 2). This pattern of inoculation via the abaxial leaf surface in our experiments is likely explained by the fact that cranberry leaves are hypostomatous (Farag and Palta, 1989; Sawyer, 1932). Although all experiments were conducted in the dark, cranberry stomata have been observed to be slow or unresponsive to changes in environmental conditions (Croft et al., 1993; Hattendorf and Davenport, 1996; Sawyer, 1932). Thus, it is possible that some stomata remained open during the experimental observations. Alternatively, even closed stomata may provide an adequate avenue of ingress for growing ice crystals.

Since cranberry leaves are hypostomatous, we hypothesize that in these cases uprights are possibly nucleated by ice propagating through stomata on the abaxial leaf surface. When bacterial droplets froze before the upright, the first leaf to subsequently be nucleated was always one upon which a bacterial droplet had been placed on the abaxial surface (Fig. 1B). Conversely, whenever an apparent intrinsic nucleation event was observed in the upright, it always occurred in the stem, and subsequently only droplets on abaxial leaf surfaces later froze (Fig. 2C). A similar freezing pattern has also been observed in IR video thermography experiments with azalea (Rhododendron sp.) leaves, which are also hypostomatous (Wisniewski and Fuller, 1999). Freezing of these leaves was induced easily through the abaxial leaf surface, but was difficult or not possible via the adaxial surface. These observations support further the idea that stomata are avenues of ice penetration into plants. This explanation is also supported by suggestions of Pearce and Ashworth (1992). They observed ice in subepidermal areas and substomatal cavities of freeze-fixed field samples of wheat leaves. In leaves frozen at $-2.4^{\circ} \mathrm{C}$, they also noted that ice was not present around vascular bundles. They suggested that ice probably is initiated either in the subepidermal areas and substomatal cavities, or on the surface of the leaf from where it propagates into the plant via stomata.

In the present study, an alternative explanation for initiation of ice in the leaves is that these areas were more likely to be the sites of ice initiation because the frozen droplets were colder than the leaf surfaces (indicated by their black appearance). However, any frozen droplet, regardless of its placement, either abaxial or adaxial, would have an equal chance of being associated with freezing of its associated leaf, and this pattern was never observed. Thus, ice propagation in and out of leaves via stomata appears to be a likely explanation for these observations.

In cases where intrinsic nucleation of the stem was observed, droplets of bacterial suspension began freezing at temperatures lower than had been experienced previously $\left(-5\right.$ to $-6{ }^{\circ} \mathrm{C}$, as compared to -1 to $-3{ }^{\circ} \mathrm{C}$ ) or remained unfrozen before the stem nucleated. This indicated a problem with the activity of the bacterial culture in use at that time. Although this development was not desirable, its occurrence allowed for observation of the pattern of ice nucleation of droplets on abaxial leaf surfaces from the opposite direction (from the plant to the droplet) than was observed previously (from the droplet to the plant). This unplanned setting meant that once the stem froze, all of the droplets placed on the leaves of the upright (in either abaxial or adaxial locations) could be tested for their capacity to be nucleated by ice inside the plant. This confirmed the previously observed pattern of ice nucleation between the inside of the plant and the plant surface occurring only on the abaxial leaf surface.

The time delay noted between freezing of the abaxially placed bacterial droplets and leaf nucleation was found to be markedly longer than the delay observed at the cut stem surface (Table 1). It also took $\approx 15$ min longer, on average, for ice on the abaxial leaf surface to induce ice initiation in the leaf than for an unfrozen droplet to be nucleated by ice from inside the leaf. Several factors may contribute to this phenomena. The air temperature at the time of nucleation of the droplets in the latter case was generally one to three degrees colder than when leaf and stem nucleation occurred in the former case. More vigorous ice crystal growth, due to the greater latent energy present, may have been impeded
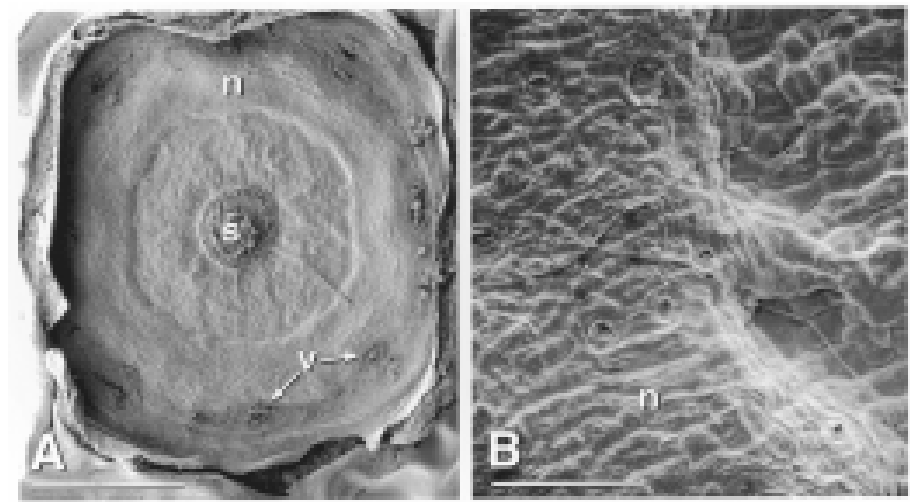

Fig. 5. Scanning electron micrographs of the calyx (distal) end of the cranberry fruit. Excised fruit ends were coated unfixed, and viewed at $10 \mathrm{kV}$. (A) overview of the calyx area (remnant calyx tissue has been removed to permit view of fruit end): area of stigma attachment (s), remnant of nectary (n), vascular bundles to anthers and petals (v). Bar represents $0.75 \mathrm{~mm}$. (B) remnant area of the nectary (n) contains stomata, while the area between the nectary and the stigma attachment does not. Bar represents $60 \mathrm{~mm}$. 
less by barriers at the leaf surface. Supercooled droplets at $-5^{\circ} \mathrm{C}$ also have a greater likelihood to freeze than those at $-2{ }^{\circ} \mathrm{C}$. Stomata in the cranberry leaf are sunken (Farag and Palta, 1989), and aspects of this structure may also have contributed to the delay of ice propagation into the leaf.

The adaxial surface of the mature cranberry leaf is known to have a highly waxy cuticle (Farag and Palta, 1989), typically with no cracks or openings. This may explain further why the adaxial surface functions as a barrier to extrinsic nucleation. Young cranberry leaves have little to no cuticle development, and have been noted to be sensitive to any temperatures below $0^{\circ} \mathrm{C}$ (Abdallah and Palta, 1989; Workmaster et al., 1997). Ice penetration may be possible from both leaf surfaces at early development stages. A similar pattern of leaf nucleation has been observed in azalea (Rhododendron L. 'Olga') (Wisniewski et al., 1997). In testing the ice nucleation patterns in cut terminal shoots of azalea, ice nucleation consistently occurred in the stems, regardless of whether Ice ${ }^{+}$ bacteria were applied to the adaxial surface. This is consistent with observations in cranberry where nucleation of the plant tissue never originated from droplets placed on the adaxial leaf surfaces.

In addition to observations of ice nucleation in the stems of azalea, Wisniewski et al. (1997) also observed stem nucleation in peach stem segments. They interpreted these nucleation patterns as likely originating from an intrinsic source. In our study, ice nucleation was observed to originate in the stem when no bacterial droplets had frozen. These cases may be instances of intrinsic stem nucleation, but since this was not investigated specifically, it cannot be confirmed at this time.

There appear to be no internal structural features in the cranberry stem to impede the propagation of ice along the stem or into leaves, as ice propagated along stems at a constant rate. Ice propagation in potato (Solanum tuberosum L.) plants has also been observed to be unimpeded (Fuller and Wisniewski, 1998). In cranberry, ice propagation was also unimpeded at the terminal bud scar at the base of the current year's growth (data not shown). In contrast, the rate of ice propagation in the stem of bean (Phaseolus vulgaris L.) plants was reported to decrease significantly at nodes, retarding the further spread of ice by $>10 \mathrm{~s}$ (Wisniewski et al., 1997).

Fruit. In this study, both attached and detached cranberry fruit supercooled to about -6 and $-7{ }^{\circ} \mathrm{C}$ for extended periods of time. The capacity of these fruit to supercool appears to be related to the presence of barriers to internal ice propagation from the pedicel or extrinsic nucleation from the plant surface. Ice in the stem was never clearly seen to propagate along the pedicel and into the ripening fruit (Fig. 3). Regardless of whether ice propagation possibly occurred in the pedicel, no attached fruit were nucleated at their pedicel (proximal) end. In all fruit experiments, ice nucleation of fruit tissue was only initiated at the calyx (distal) end of the fruit (Fig. 4). Red (ripe) berries typically supercooled to colder temperatures and for longer durations than blush (unripe) berries. In support of these results, increased cold hardiness of cranberry fruit during ripening has been reported (Abdallah and Palta, 1989).

Physical changes in the developing and ripening cranberry fruit may contribute to its capacity to supercool by limiting the potential for extrinsic nucleation. It is possible that as the cranberry fruit ripens, vascular connection to the fruit is greatly reduced. In field-grown cranberries, after the period of greatest fruit enlargement, the pedicel turns brown, dries, and decreases in diameter. Lower water content in the pedicel may contribute to the supercooling ability of the fruit by creating a barrier to ice propagation. Alternatively, if that water does freeze, it may not be detectable by IR video thermography at the current levels of resolution. As the cranberry fruit ripens, its cuticle becomes waxier and thicker (Farag and Palta, 1989), creating a barrier to extrinsic nucleation.

The calyx area of the fruit was observed to be the only portion of the fruit where ice was initiated. SEM shows the presence of stomata in the remnant area of the nectary (Fig. 5A and B). In this area, stomata with varying degrees of openness were observed. Stomata are possible avenues of ice penetration into leaves. A similar scenario may apply to fruit. Nectaries do not have any vascular bundles, but are located typically near vascular tissue (Weberling, 1989). In controlled freezing tests, we have observed watersoaking in freeze-injured fruit at both the calyx end of the fruit and along vascular strands in the pericarp tissue. Waxy deposits on the remnant nectary surface may act as a barrier or impediment to ice penetration, thus protecting the fruit from extrinsic nucleation.

Results of this study provide additional evidence that IR video thermography has great potential for the study of ice nucleation and propagation in plants. How and where ice is initiated in fruiting woody plant tissue has significant implications for the fate of different tissues during a frost event. In cranberry, areas of stomatal distribution, such as the abaxial sides of leaves and the nectary, were observed to be areas vulnerable to extrinsic ice penetration. Intrinsic nucleation may also occur in the stem. Barriers to ice propagation contribute to a tissue's capacity to supercool. Limited or no ice nucleation appears to occur in cranberry fruit pedicels at the time of fruit ripening. Ripened fruit supercool to lower temperatures and for longer durations than white or blush fruit. Ripened cranberry fruit may often freeze independently of the rest of the plant.

\section{Literature Cited}

Abdallah, A.Y. and J.P. Palta. 1989. Changes in the freezing stress resistance of the cranberry leaf, flower bud, and fruit during growth and development. Acta Hort. 241:273-276.

Andrews, P.K., E.L. Proebsting, Jr., and D.C. Gross. 1986. Ice nucleation and supercooling in freeze-sensitive peach and sweet cherry tissues. J. Amer. Soc. Hort. Sci. 111:232-236.

Ashworth, E.N. 1982. Properties of peach flower buds which facilitate supercooling. Plant Physiol. 70:1475-1479.

Ashworth, E.N. 1984. Xylem development in Prunus flower buds and the relationship to deep supercooling. Plant Physiol. 74:862-865.

Ashworth, E.N. 1992. Formation and spread of ice in plant tissues. Hort. Rev. 1992: 215-255.

Ashworth, E.N. and F.B. Abeles. 1984. Freezing behavior of water in small pores and the possible role in the freezing of plant tissues. Plant Physiol. 76:201-204.

Ashworth, E.N., J.A. Anderson, G.A. Davis, and G.W. Lightner. 1985. Ice formation in Prunus persica under field conditions. J. Amer. Soc. Hort. Sci. 110:322-324.

Ashworth E.N. and G.A. Davis. 1984. Ice nucleation within peach trees. J. Amer. Soc. Hort. Sci. 109:198-201.

Ashworth, E.N., T.J. Willard, and S.R. Malone. 1992. The relationship between vascular differentiation and distribution of ice within forsythia flower buds. Plant Cell Environ. 15:607-612.

Cary, J.W. and H.F. Mayland. 1970. Factors influencing freezing of supercooled water in tender plants. Agron. J. 62:715-719.

Ceccardi, T.L., R.L. Heath, and I.P. Ting. 1995. Low-temperature exotherm measurement using infrared thermography. HortScience 30:140-142.

Croft, P.J., M.D. Shulman, and R. Avissar. 1993. Cranberry stomatal conductivity. HortScience 28:1114-1116. 
Cross, C.E. 1953. Cranberry flowers and the set of fruit. Cranberries 17(12):7-9.

Dana, M.N. 1990. Cranberry management, p. 334-362. In G.J. Galletta and D.G. Himelrick (eds.). Small fruit crop management. Prentice Hall, Englewood Cliffs, N.J.

Farag, K. and J.P. Palta. 1989. Ultrastructure and surface morphology of cranberry plant (Vaccinium macrocarpon Ait.) with reference to ethrel penetration. Acta Hort. 241:378-384.

Fuller, M.P. and M. Wisniewski. 1998. The use of infrared thermal imaging in the study of ice nucleation and freezing of plants. J. Therm. Biol. 23:81-89.

Gross, D.C., E.L. Proebsting, Jr., and H. MacCrindle-Zimmerman. 1988. Development, distribution, and characteristics of intrinsic, nonbacterial ice nuclei in Prunus wood. Plant Physiol. 88:915-922.

Hattendorf, M.J. and J.R. Davenport. 1996. Cranberry evapotranspiration. HortScience 31:334-337.

Le Grice, P., M.P. Fuller, and A. Campbell. 1993. An investigation of the potential use of thermal imaging technology in the study of frost damage to sensitive crops. Proc. 6th Intl. Conf. Biol. Ice Nucleation. Univ. Wyoming, Laramie.

Levitt, J. 1980. Responses of plants to environmental stresses. Vol. 1. Chilling, freezing, and high temperature stresses. 2nd ed. Academic Press, Orlando, Fla.

Lindow, S.E. 1995. Control of epiphytic ice nucleation-active bacteria for management of plant frost injury, p. 239-256. In: R.E. Lee, G.J. Warren, and L.V. Gusta (eds.). Biological ice nucleation and its applications. Amer. Phytopathol. Soc., St. Paul, Minn.

Lindow, S.E., D.C. Arny, and C.D. Upper. 1982. Bacterial ice nucleation: A factor in frost injury to plants. Plant Physiol. 70:1084-1089.

Lucas, J.W. 1954. Subcooling and ice nucleation in lemon. Plant Physiol. 29:245-251.

Pearce, R.S. and E.N. Ashworth. 1992. Cell shape and localisation of ice in leaves of overwintering wheat during frost stress in the field. Planta.
188:324-331.

Price, W.S., I. Hiroyuki, Y. Arata, and M. Ishikawa. 1997. Visualisation of freezing behaviours in flower bud tissues of cold-hardy Rhododendron japonicum by nuclear magnetic resonance micro-imaging. Austral. J. Plant Physiol. 24:599-605.

Proebsting, E.L., Jr., P.K. Andrews, and D.C. Gross. 1982. Supercooling young developing fruit and floral buds in deciduous orchards. HortScience 17:67-68.

Quamme, H.A., C. Stushnoff, and C.J. Weiser. 1972. The relationship of exotherms to cold injury in apple stem tissues. J. Amer. Soc. Hort. Sci. 97:608-613.

Quamme, H.A., W.A. Su, and L.J. Veto. 1995. Anatomical features facilitating supercooling of the flower within the dormant peach bud. J. Amer. Soc. Hort. Sci. 120:814-822.

Sawyer, W.H. 1932. Stomatal apparatus of the cultivated cranberry, Vaccinium macrocarpon. Amer. J. Bot. 19:508-513.

Single, W.V. 1964. Studies on frost injury in wheat. II. Ice formation within the plant. Austral. J. Agr. Res. 15:869-875.

Weberling, F. 1989. Morphology of flowers and inflorescences. Cambridge Univ. Press, London.

Wisniewski, M. and M. Fuller. 1999. Ice nucleation and deep supercooling: New insights using infrared thermography, p. 105-118. In: R. Margesin and F. Schinner (eds.). Cold-adapted organisms: Ecology, physiology, enzymology, and molecular biology. Springer Verlag, Berlin.

Wisniewski, M., S.E. Lindow, and E.N. Ashworth. 1997. Observations of ice nucleation and propagation in plants using infrared video thermography. Plant Physiol. 113:327-334.

Workmaster, B.A.A., J.P. Palta, and J.D. Smith. 1997. Seasonal frost hardiness changes in the cranberry plant. HortScience. 32:537 (abstr.). Yelenosky, G. 1991. Apparent nucleation and freezing in different parts of young citrus trees during controlled freezes. HortScience 26:576579. 